\title{
The XIV International Materials Research Congress (IMRC-2005) www.viep.buap.mx/imrc2005.htm
}

Every year, the Academia Mexicana de Ciencia de Materiales (AMCM) organizes the International Materials Research Congress. This meeting provides an interactive forum for discussing advances in synthesis, characterization, properties and processing, applications, basic research trends, and education in the area of materials research.

One of the main goals of the AMCM is to promote relationships and academic interchange with other societies and with those in fields related to materials research in order to improve research collaborations. In 2004, the participation of the Asociación Mexicana de Microscopía, the Iztapalapa Science Sol-Gel and Technology Society, the Academia Mexicana de Química Inorgánica, and NACE International improved the congress in many aspects; following this direction, in 2005 the AMCM, the International Union of Materials Societies (IUMRS), and NACE International organized a single congress encompassing the XIV International Materials Research Congress (IMRC2005), the "Materials World Network: The Next Ten Years" symposium, and the NACE International, Section Mexico, meeting. The congress was held in Cancun,

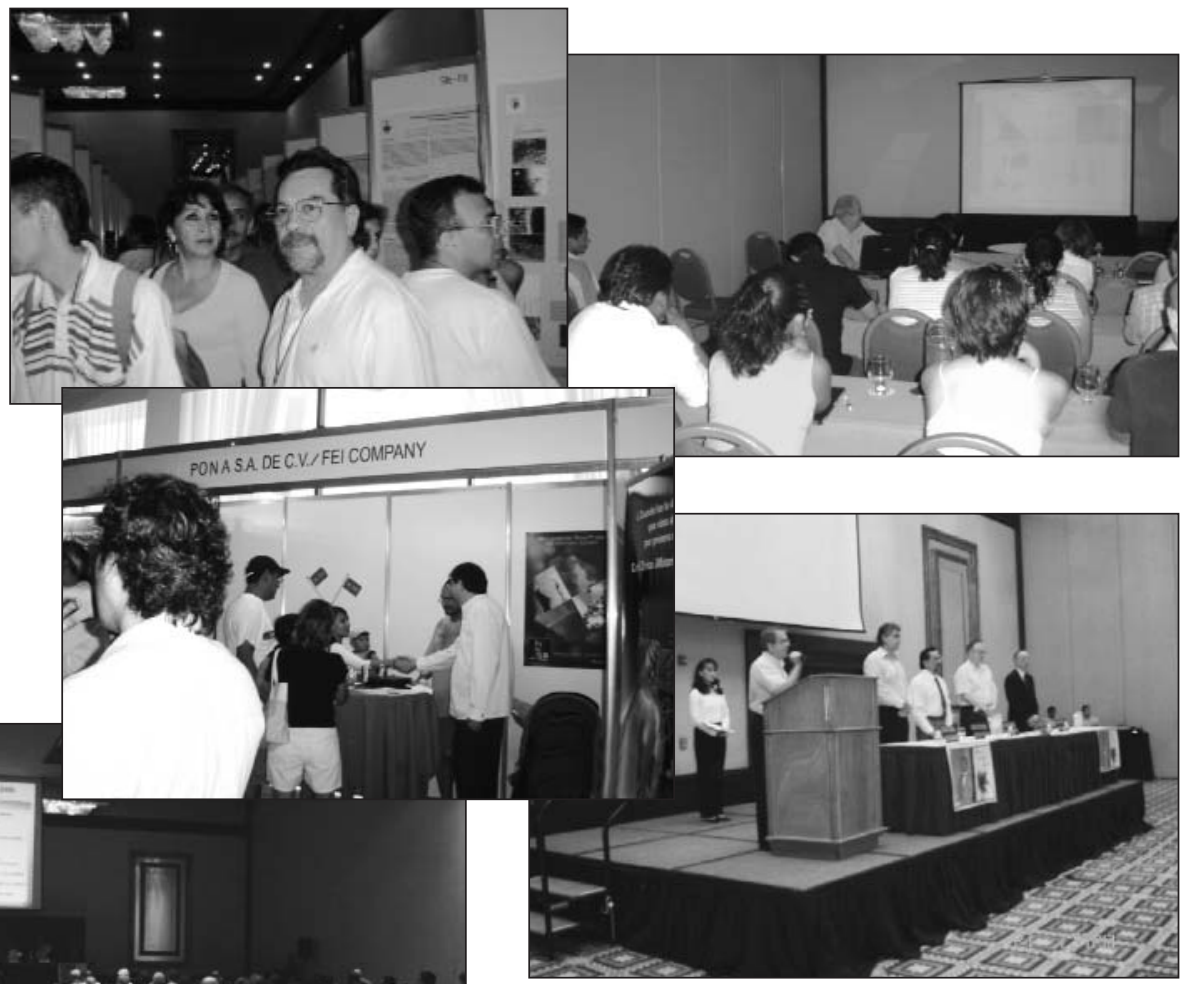

\section{Mexico, August 21-25, 2005.}

During the congress, colleagues, students, sponsors, and exhibitors created a multidisciplinary forum and provided an invaluable platform that allowed interaction among researchers and students from all over the world. Participants learned firsthand about new directions in materials research topics. The congress was successful this year in promoting relationships with other materials research societies, increasing the participation of Mexican and non-Mexican researchers and students, and improving the academic interaction of Mexican researchers and students with researchers of other countries. In addition, 120 scholarships were given. The total number of participants was 1000 .

The opening ceremony of the congress was carried out by Jaime Parada Ávila, general director of the National Council of Science and Technology, who emphasized the relevance and importance of the congress to the development of science and technology in Mexico. Parada was accompanied by Pedro Hugo Hernández Tejeda, president of the Mexican Academy of Materials Science; Arden Bement, director of the U.S. National Science Foundation; Robert Chang, general secretary of IUMRS; and Lorenzo Martínez Gómez, past president of NACE International, Section Mexico.

The technical program consisted of 21 symposia and 1221 presentations divided among oral talks and poster presentations, with more than 150 invited speakers from 20 universities and five countries. Other events included 10 tutorial courses; a "Women in Science" luncheon; and an exhibition of instruments and equipment, products, and services in the field of materials research. Posters were given special recognition, including a first-place award for Technology Innovation and honorary mentions.

Three new symposia were added to the congress: Hybrid Materials, Ecomaterials, and the Inter-American Collaboration in Materials. Plenary speakers included
The XIV International Materials Research Congress (IMRC-2005), held in Cancun, Mexico, in August 2005, provided a forum for researchers and students worldwide to exchange research information.
Bernabé Rivas (Universidad de Chile) on functional polymer materials; Alvin D. Compaan (the University of Toledo) on photovoltaics; and Lih J. Chen (National Tsing Hua University) on in situ ultrahigh-vacuum transmission electron microscope investigations of dynamical changes of nanostructures on silicon and silicon bicrystals.

IUMRS held a special symposium, titled the "Materials World Network: The Next Ten Years." The goals of this event were to involve active members of the global materials community in network planning and to cast a new vision for the future of the Materials World Network. The special symposium featured plenary speakers for international discussion panels, along with opportunities for working groups and networking sessions to convene.

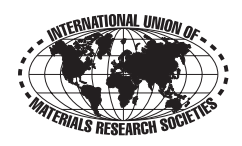




\section{Conference on High Technology Plasma Processes to $\mathrm{Be}$ Held in Russia in 2006}

The conference on High Technology Plasma Processes (HTPP9) will be held in St. Petersburg, Russia, May 29-June 4, 2006. The conference is sponsored by the European Materials Research Society (E-MRS), European High Temperature, Russian Academy of Sciences (RAS), and Russian Funds for Basic Research. It is organized by Ph. Rutberg (Institute for Electrophysics and Electric Power, RAS), M. Fedorov (State Polytechnic University of St. Petersburg), J. Amouroux (Université Pierre et Marie Curie/ ENSCP), P. Fauchais (University of Limoges), and J. Van der Mullen (University of Eindhoven).

The conference addresses issues of interest to researchers, scientists, engineers, and experts in the field of plasma processes and their applications. Conference topics include

- plasma sources and new electrical devices;

- electrical discharges in gas and liquids;

- on-line control and diagnostics;

- surface treatments by plasma processes;

- plasma processes for new materials; and

- plasma deposits for renewable energy;

TTP9 Thermal Plasma Processes will be held as Symposium S.

The official language of the conference is English, and accepted papers will be published in English in the journal High Temperature Material Processes; selected papers will be published in a special issue of the journal of the Russian Academy of Sciences.

For more information, access the E-MRS Web site at wwwemrs.c-strasbourg.fr/2006_SPRING/HTPP9.pdf.

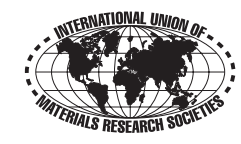

\section{Chapter, \\ "friendly competition" among MRS Chapters.}

The premise is simple. We've come up with a theme, Biology-The Next Frontier of Materials Science and Engineering, and we want to see just what your members can do with it.

That's it. We're giving you the theme and not much more. Your challenge is to come up with a creative program or activity that relates to biology and materials scienec \& enginecring... and then make it happen!

Details for the competition can be found on our Web site: www.mrs.org/university/2006challenge

So get your Chapter together and set the creative juices flowing. It's a great way to energize your membership, increase student involvement, and showeasc your Chapter.

Deadline for entries is April 1, 2006. The winning Chapter will be announeed May 1, 2006 and will be featured in a summer issue of the MRS Bulletin. Don't lose another minute. The Chaper' hallenge starts Now!

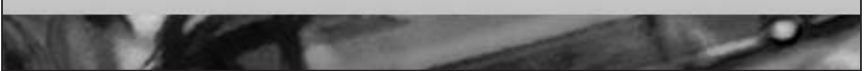

\section{Precision Heating to $1200^{\circ} \mathrm{C}$ in 24 seconds, for under 10K?}
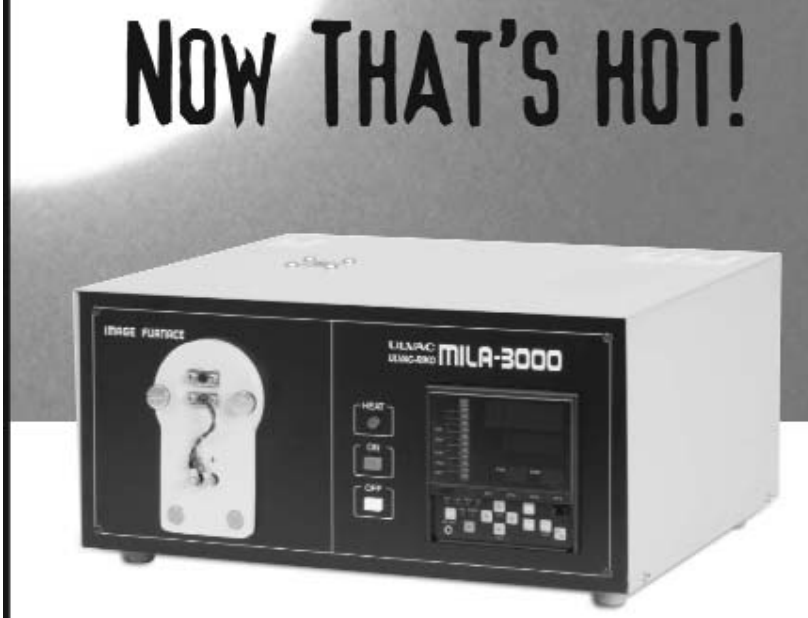

Anneal your small samples faster and with better control using the programmable MILA-3000 tabletop furnace. Ulvac's Mini-Lamp Annealing System can rapidly heat and cool samples with it's infrared gold image furnace, providing precision high temperature control, clean heating and versatile atmosphere selection.

MILA-3000 Features:

- High controlled heating rates of $50^{\circ} \mathrm{C} / \mathrm{s}$

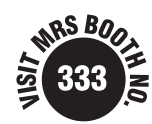

- Sample size $20 \times 20 \times 20 \mathrm{~mm}$

- Air, vacuum and inert/reactive gas atmosphere

- Temperature uniformity of $+/-2^{\circ} \mathrm{C}$

- Low power consumption $(1 \mathrm{~kW})$

For all your annealing and thermal processes, turn on the heat with the MILA-3000!

\section{ULVAC}

Phone: 978-686-7550

www.ulvac.com

sales@ulvac.com 